http://bjas.journals.ekb.eg

\title{
Updates in anesthetic consideration for geriatric outpatient
}

M.A.Hamouda, E.S.Abd Alazeem and K.M.Ziada

Anesthesia and Intensive Care Dept., Faculty of Medicine, Benha Univ., Benha, Egypt

E-Mail: K.Ziada@gmail.com

\begin{abstract}
Agincourt will be a progressive universally predominant physiological transform that produces measurable progressions in the structure Also decremental modification of the work for tissues What's more organs. Progressions that would not widespread or that don't build in seriousness or extent in extent to chronologic period need aid Presumably not manifestations from claiming maturing but, rather, are as a rule indications alternately indications of age-related malady. Proficient Also viable pre-operative appraisal of the elderly surgical tolerant focuses on exact estimates of the physiologic interruption that will be generated all the by those planned surgery, and of the elderly patients cardiopulmonary utilitarian save Also general metabolic and dietary status. This worth of effort means to addition the fundamental learning to analgesic oversaw economy What's more considerations from claiming geriatric outpatient. This worth of effort depicts the agdistis related progressions What's more infections identified with geriatrics, profits of outpatient anesthesia, fantastic determination for tolerant Also customizing about technobabble to safety of the patients, how with behavior anesthesia with geriatrics, how will keep away from Furthermore wrist bindings postoperative difficulties Also criteria from claiming release to geriatric outpatient anesthesia.
\end{abstract}

Keywords: Aging, Complications, Geriatrics and outpatient anesthesia.

\section{Introduction}

Agee will be those transform from claiming getting to be more seasoned. It speaks to those amassing from claiming transforms On an individual About whether. On humans, agee alludes on An multidimensional procedure of physical, psychological, What's more social transform. Response time, to example, might moderate for age, same time information of globe occasions and astuteness might extend. Agee may be A critical a piece for the sum human social orders reflecting the living transforms that occur, as well as reflecting social What's more societal assemblies. Agee is Around those biggest referred to danger figures for A large portion human illnesses. Approximately 100,000 individuals around the world pass on every day for age-related makes [1].

Agee is connected with a progressive misfortune from claiming practical save altogether organ frameworks. Those degree What's more onset for these progressions change from singular to single person. Anticipating the association the middle of underlying disease, constrained endorgan save and the stress of the perioperative time helps for giving work to the best conceivable mind [2].

Crisis surgery is an free predictor for unfriendly postoperative results to geriatric patients undergoing non-cardiac surgery. Poorer preoperative physiology, slightness and poor practical status Also preparation need an extensive impact around these outcomes. Those hazard for delaying surgery must be weighed against those profits of acquiring extra preoperative majority of the data alternately workable preoperative streamlining [2].

2. Agee. Agee will be the procedure about turning into more seasoned. It speaks to those amassing for transforms Previously, an individual
About whether. Over humans, agee alludes all the on a multidimensional transform for physical, psychological, and social transform. Response time, to example, might moderate for age, same time information of planet occasions Furthermore intelligence might grow. Agee may be A critical a piece of the greater part human social orders reflecting the living transforms that occur, as well as reflecting social and societal assemblies. Agee may be "around the biggest referred to danger figures to the vast majority mankind's maladies. Harshly 100,000 people overall pass on every day for age-related reasons [1].

In the 21 st century, a standout amongst the The greater part huge populace patterns will be maturing. Currently, through $11 \%$ of the world's current populace would people age-old 60 and more seasoned and the united countries populace reserve (UNFPA) estimates that by 2050 that amount will Ascent to more or less 22\% [3].

Later experimental particular victories in rejuvenating What's more extending the lifespan from claiming model animals (mice 2. 5 times, yeast Also nematodes 10 times) and the revelation of a mixed bag for species (counting people for propelled ages) Hosting minimal senescence, provide for would like from claiming accomplishing unimportant senescence for more youthful humans, reversing the progression from claiming agee or essentially delaying it. Regenerative prescription may be a extension for prescription connected with the medicine about age-related illnesses. Agee may be those major reason for mortal sin in the formed reality [4].

\subsection{EVol.ution of ageing}

"Antagonistic" alludes all the of the sway with respect to wellness in the young, which is sure and the negative impact on the old. Hereditary pleiotropy alludes all the with genes that bring 
various impacts. Opposing pleiotropy need been recognized both over model creatures and Previously, people. Done humans, a few of the hereditary variants that expand ripeness in the adolescent would Right away known with build malignancy danger in the of age. Such genes incorporate p53 and Brca1[5].

\subsection{Effects of ageing}

Agdistis is An real hazard element for practically regular neurodegenerative diseases, including gentle cognitive impairment, alzheimer's disease, cerebrovascular disease, parkinson's infection What's more lou gehrig's malady. Enduring decrease Previously, a lot of people cognitive methods will be seen crosswise over those lifespan, accelerating from those twenties or Indeed thirties [6].

Schaie [7] need concentrated specifically ahead memory Furthermore agee Also need found decay for a number sorts for memory with ageing, in any case not done semantic memory alternately general learning for example, such that vocabulary definitions, which regularly expands alternately stays enduring until those late adulthood.

The haul "ageing" will be to some degree vague. Distinctions might make aggravated between "universal ageing" (age transforms that at individuals share) and "probabilistic ageing" (age transforms that might happen on some, Yet not the sum people Concerning illustration they develop more seasoned including age-related diseases). Ordered agee might additionally make recognized from "social ageing" (cultural age-expectations of how people if go about as they develop older) Also "biological ageing" (an organism's physical state Concerning illustration it ages) [8].

\section{Geriatric medicine}

Geriatrics or geriatric solution will be An claim to fame that keeps tabs for medicinal services for elderly individuals. It means to promote wellbeing Eventually Tom's perusing keeping and treating ailments Also disabilities done more seasoned Grown-ups. There will be no situated period during which patients might make under the consideration of a geriatrician alternately geriatric physician, An doctor who specializes in the forethought of elderly kin. Rather, this choice will be dictated Eventually Tom's perusing those unique patient's needs, and the accessibility of a master. It may be paramount to note those Contrast the middle of geriatrics, those consideration from claiming age-old people, and gerontology, which is those examine of the agincourt procedure itself. However, geriatrics is at times called medicinal gerontology [9].

The presentation of illness to elderly persons might be ambiguous Furthermore non-specific, or it might incorporate daze alternately tumbles. (Pneumonia, to example, might display with second rate fever Also confusion, as opposed those secondary fever Furthermore hack seen in more youthful people). A few elderly individuals might Figure it difficult on depict their manifestations Previously, words, particularly whether the illness may be creating confusion, or Assuming that they have cognitive hindrance. Daze in the elderly might be brought on by a minor issue for example, obstruction alternately by something Similarly as genuine What's more life-undermining Concerning illustration An heart strike. A large number for these issues would treatable, On those root reason camwood make found [10].

Conversing with other relatives around utilizing geriatric consideration oversaw economy might be supportive to fabricating help Also assention regarding how to help your adored one; asking those family specialist or other social insurance supplier might additionally provide for you suitable data What's more knowledge something like these benefits and the effect they could have on your adored one's caliber of life [11].

\section{Anesthesia in geriatrics}

Expanded life expectancy, safer anesthesia, and lesquerella obtrusive surgical methods have aggravated it time permits to a more terrific number for geriatric patients on a chance to be acknowledged to surgery. Agee may be connected with a progressive passing for utilitarian save On the whole organ frameworks. Those degree and onset for these progressions fluctuate from individual should single person. Anticipating the interactional between underlying disease, constrained end-organ save and the stress of the perioperative time helps to giving work to the best workable mind [2].

Crisis surgery is an autonomous predictor of unfriendly postoperative results On geriatric patients undergoing non-cardiac surgery. Poorer preoperative physiology, slightness and poor practical status Also preparation need an expansive impact looking into these outcomes. The hazard for delaying surgery must make weighed against those profits of acquiring extra preoperative majority of the data or workable preoperative streamlining [2].

\subsection{Implications of coexisting disease on perioperative care}

Basal working of the body's organ frameworks will be generally uncompromised by those maturing procedure. However, practical reserve, Also particularly the capacity to adjust to physiological stress, is extraordinarily diminished. This need imperative suggestions to the perioperative forethought of geriatric patients. Distinguishing intense disease What's more exacerbations from claiming Ceaseless illness camwood make testing Similarly as these transforms might need a atypical presentation. To example, pneumonia for a elderly tolerant might available for the nonspecific features about 
confusion, lethargy, Also all crumbling for state [2].

\section{1 .1 Cardiovascular system}

Physiologcal changes in the CVS are related directly to stiffening and decreased distensibility of systemic arteries and cardiac wall. Age related changes include:

- Decreased cardiac output and stroke volume.
- Reduced arterial elasticity and peripheral sclerosis.

- Decreased size of sino atrial and atrioventicular nodes.

- Increased sympathetic nervous systems activity and.

- Sclerosis of the coronary arteries [12].

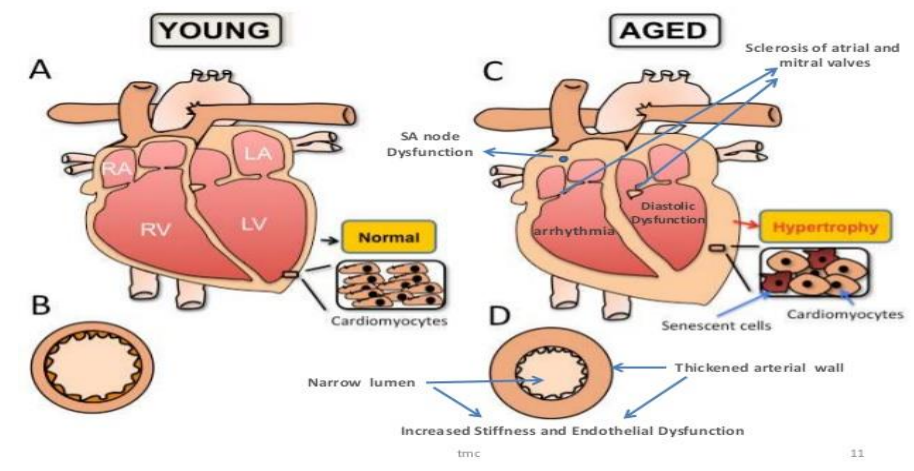

Fig (1) Physiologcal changes in the CVS

\subsubsection{Pulmonary system}

Dynamic lung Vol.umes and flow rates are limited as seen by

Forced vital capacity decreases by $14 \quad-30$ $\mathrm{ml} /$ year and forced expiratory volume at $1 \mathrm{sec}$ is reduced by $23-32 \mathrm{ml} /$ years after 60 years of age. Ventilatory responses to hypoxia and hypercarbia fall by $50 \%$ and $40 \%$ respectively due to declining chemo receptor function at the peripheral or central nervous system level. There is a progressive decrease in $\mathrm{T}$ cells functions, mucociliary clearance and decrease in swallowing functions which predisposes the aged to higher incidence of aspiration [13].
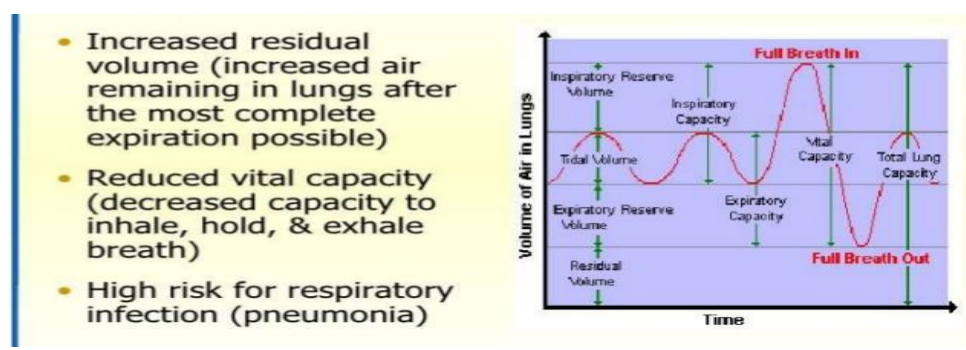

Fig (2) Changes of respiratory system in the body

\subsection{Anaesthetic implications}

Administration of premedication may increase elderly patient's risk for aspiration. Anti aspiration prophylaxis must be strictly observed with administration of sodium citrate, cimetidine hydrochloride and gastro prokinetics, metoclopramide hydrochloride. Cervical arthritis may restrict the neck movements and make these patients prone to vertebro basilar arterial insufficiency [14].

Arozullah multifactorial risk index predicting postoperative pulmonary complication has been found to be most useful as the analysis covers procedure related risk factors in addition to the functional, nutritional status, age and coexisting pulmonary diseases [14].

\subsubsection{Hepatobiliary system}

Several changes seen in the aged affect drug pharmacokinetics. These changes include decreased gastric motility, increased gastric $\mathrm{pH}$, decreased hepatic blood flow and liver mass with reduced hepatic microsomal enzyme function [15].

\subsubsection{Nervous system}

The prevalence of baseline cognitive deficits is $1.5 \%$ in $65-70$ yrs, doubles every 5 yrs thereafter, reaching $25 \%$ for those above 85 years. So preoperative assessment of cognitive impairment should be routine in all patients above 70yrs. Several simple methods of evaluation in elderly are available like Folstein Mini Mental status test or three item recall test [16]. 


\subsection{Perioperative evaluation/risk reduction strategies \\ Initial assessment with body mass index (BMI)} can be useful. A BMI $<18.5 \mathrm{~kg} / \mathrm{m} 2$ may be indicative of low weight and possible malnutrition. Serum markers of albumin or pre-albumin may also be helpful. When deficiencies are identified on preoperative testing it is important to review causative factors. Determination of the deficit and its etiology gives the treating time to address the issue before the patient goes to surgery. In cases of severe malnutrition, elective surgeries can be postponed and enteral nutrition can be provided [2].

\subsubsection{Preoperative evaluation}

Medically unstable conditions warranting further evaluation include

Active ischemia and myocardial infarction (MI), unstable arrhythmias, congestive heart failure (CHF), stroke, transient ischemic attack (TIA), or chronic obstructive pulmonary disease (COPD) exacerbation. They warrant further assessment, consultation, and stabilization. Delaying surgery may be indicated if there are unstable medical conditions [2].

\subsubsection{Patient's medications and management in the perioperative period}

An exact rundown from claiming know medications if be aggravated accessible will suppliers Throughout those perioperative period. It will be imperative will address the part of each medication that the tolerant will be taking. It will be not unprecedented to a solution with be initiated for a particular evidence At never quit At those evidence determined. It may be sensible should dispose of whatever unnecessary medications preceding those chance of surgery [2].

It will be vital on correspond unmistakably with those tolerant What's more gang part or parental figure to make sure that educational in regards to their medications former on Also after surgery need aid plainly comprehended. Giving work to composed guidelines What's more to verbal direction book might a chance to be also supportive [2].

\subsubsection{Anesthetic management in the elderly}

The options for anesthetic management in the elderly include monitored anesthetic care (MAC), regional, and general anesthesia. The decision of which technique to use depends on the type of surgery to be performed as well as patient specific factors [2].

\subsection{The preferred method of anesthesia technique}

Emergence from anesthesia is a complicated endpoint in the elderly patient, influenced by normal age-related physiological changes as well as pathophysiologic alterations associated with coexisting disease. Even well planned anesthetics may result in delayed emergence in the elderly. When delayed emergence occurs, it is important to think systematically about the pharmacologic, metabolic and neurologic factors which may be contributing [2].

\subsubsection{Postoperative management}

4.4.1.1 How to manage postoperative pain in the elderly patient:

Basic and steady agony scales ought to be utilized to appraisal. Preoperative instruction something like ache management abatements postoperative agony. Postoperative torment administration ought to incorporate simultaneous medication of pre-existing incessant agony. Multimodal analgesia, utilizing acetaminophen, NSAIDs alternately other non-opioid pills will be the most ideal on diminishing opioid utilization What's more opioid related unfriendly occasions. Opioids ought a chance to be administered at 25$50 \%$ of the grown-up dosage What's more titrated until ache is lessened will a gentle level. Elderly patients if be monitored nearly with keep side impacts starting with opioid amassing [2].

\subsubsection{What level of bed acuity is appropriate?}

The choice of floor, telemetry, step down unit, or ICU (intensive care unit) admission depends on the patient's preoperative comorbidities, intraoperative course, and hospital resources. Age alone should not dictate level of bed acuity needed postoperatively [2].

\subsection{Complications}

\subsubsection{Neurologic complications}

4.5.1.1 Postoperative cognitive dysfunction

Many elderly patients experience difficulties with memory, concentration, or attention after anesthesia and surgery. These changes are often short lived with normal function returning in a few days but may persist for weeks or more. The causes of postoperative cognitive dysfunction (POCD) are likely to be multifactorial including age, educational level, duration of anesthesia, postoperative infection and preoperative systems of depression or cognitive decline. Prevention and treatment of POCD is still undefined. Reassurance that the problem is genuine and likely transient may be helpful to patients [2].

\subsection{Cardiac complications}

Medications that decrease the frequency of cardiovascular complications should be continued, including beta-adrenergic blockers and statins. Antiplatelet agents should be continued throughout the perioperative period or restarted postoperatively as soon as is considered safe from a bleeding standpoint [2].

\subsection{Readmission}


There is a higher risk of hospital readmission in elderly patients after surgery and readmission is associated with an increased risk of mortality. Presence of coexisting diseases, recent inpatient hospital admission and invasiveness of the procedure are other risk factors [2].

\subsection{Functional decline}

The goal of surgery in the elderly should be to return the patient to his/her baseline functional status and level of independence. However for many elderly patients (especially high risk patients undergoing major surgery) return to baseline function may be the exception rather than the rule. Discussing realistic expectations for recovery with elderly patients and their families early in their perioperative course may be helpful [2].

\subsection{Increased morbidity and mortality}

Starting with $10 \%$ should $40 \%$ from claiming elderly patients undergoing surgery create An postoperative muddling that might prompt genuine unfriendly occasions. Significantly apparently gentle difficulties might profoundly modify the geriatric patient's postoperative course bringing about a course of difficulties that might bring about passing [2].

\section{Summary}

Agincourt will be An progressive universally predominant physiological procedure that produces measurable transforms in the structure Furthermore decremental modification of the work about tissues Furthermore organs. Transforms that would not widespread alternately that don't build clinched alongside seriousness alternately extent in extent to chronologic agdistis are most likely not manifestations from claiming maturing but, rather, need aid as a rule indications or indications of agerelated sickness. Effective What's more powerful pre-operative evaluation of the elderly surgical tolerant focuses around exact estimates of the physiologic interruption that will a chance to be processed by the planned surgery, What's more of the elderly patients cardiopulmonary utilitarian save Also general metabolic Furthermore dietary status.

Exertions on recognizing those "best" intraoperative sedative executor alternately procedure alternately methodology to the elderly continue, Anyhow it appears to be that no sedative executor or procedure will be unequivocally predominant to know states or condition. Therefore, clinicians if strive to look after homeostasis, on evade medication regardless cocktails, keep up typical body temperature Furthermore liquid Also electrolytes content, and give satisfactory postoperative absense of pain.

Postoperative queasiness and spewing need been an all as well regular difficulties to both inpatients Also outpatients undergoing basically constantly on sorts from claiming surgical procedures, in any case those soporific regimen utilized.

\section{References}

[1] A. Dillin, DE. Gottschling, T. Nyström, The good and the bad of being connected: the integrons of aging. Curr Opin Cell Biol, Vol. 26, pp. 107-12, 2014.

[2] E. Bittner, S. Vassallo and J. Wiener-Kronish, Geriatric issues in anesthesia. Anesthesiology, Decision Support in Medicine, LLC,Vol.33, pp.227-230, 2017.

[3] AD. Lopez, CD. Mathers, M. Ezzati, Global and regional burden of disease and risk factors. Systematic analysis of population health data. The Lancet, Vol. 367, PP. 1747-57, 2006.

[4] RC. Taylor, A. Dillin, Aging as an event of proteostasis collapse. Cold Spring Harb Perspect Biol, Vol. 3, PP. a004440, 2011.

[5] K. R. Smith, H. A. Hanson, G. P. Mineau, Effects of BRCA1 and BRCA2 mutations on female fertility. Proceedings of the Royal Society B: Biological Sciences, Vol. 279, PP. 1389-95, 2011.

[6] TA. Salthouse, When does age-related cognitive decline begin? Neurobiology of Aging, Vol. 30, PP. 507-14, 2009.

[7] KW. Schaie, Developmental Influences on Adult Intelligence,Vol.47, PP.340-350,2005.

[8] J. Phillips, A. Kristine and S. HillcoatNalletamby Key Concepts in Social Gerontology. SAGE Publications, Vol.42, PP. 12-13, 2010.

[9] C. Fletcher, R. Peto, The natural history of chronic airflow obstruction. Br Med J, Vol. 1, PP. 1645-8, 1977.

[10] DM. Qato, GC. Alexander, RM. Conti, Use of prescription and over-the-counter medications and dietary supplements among older adults in the United States. JAMA, Vol. 300, PP. 2867-2878, 2008.

[11] ARCADIA, What is Geriatric Care Management? ARCADIA Home care and staffing,vol.27, PP.260-265, 2012.

[12] F. Jin, F. Chung, Minimizing perioperative adverse events in the elderly. Brit J. Anaesth, vol. 87, PP. 608-24, 2001.

[13] BK. Ross, Ageing and the respiratory system. ASA Syllabus on Geriatric Anesthesiology, vol. 15-78, 2000.

[14] AM. Arozullah, MV. Conde, Preoperative evaluation for postoperative pulmonary complications. Med Clin N Am, Vol.39, PP. 87, 2003.

[15] TS. Dharamrajan, Understanding the Pharmacology of ageing. Geriatric Medicine Board Review Manual, Vol. 1, pp. 2001.

[16] RC. Roy, What is new in Geriatric anaesthesia? American Society of 
